\title{
Social, ethical and communication aspects of uncertainty management
}

\author{
C. Turcanu ${ }^{1, *}$, T. Perko ${ }^{1}$, S. Baudé ${ }^{2}$, G. Hériard-Dubreuil ${ }^{2}$, N. Zeleznik ${ }^{3}$, D. Oughton ${ }^{4}$, Y. Tomkiv ${ }^{4}$, \\ R. Sala ${ }^{5}$, C. Oltra ${ }^{5}$, V. Tafili ${ }^{6}$, L. Benighaus ${ }^{7}$, C. Benighaus ${ }^{7}$, M. Maitre ${ }^{8}$, T. Schneider ${ }^{8}$, P. Crouail $^{8}$, \\ T. Duranova ${ }^{9}$ and I. Paiva ${ }^{10}$
}

${ }^{1}$ SCK-CEN-Belgian Nuclear Research Centre, Mol, Belgium.

${ }^{2}$ MUTADIS, Paris, France.

3 EIMV - Elektroinštitut Milan Vidmar, Ljubljana, Slovenia.

${ }^{4}$ NMBU/CERAD - Norwegian University of Life Sciences, Centre for Environmental Radioactivity, Ås, Norway.

${ }^{5}$ CIEMAT-CISOT - Sociotechnical Research Centre, Barcelona, Spain.

${ }^{6}$ EEAE-Greek Atomic Energy Commission, Athens, Greece.

7 DIALOGIK - non-profit institute for communication and cooperation research, Stuttgart, Germany.

${ }^{8}$ CEPN Centre d'étude sur l'Évaluation de la Protection dans le domaine Nucléaire, Fontenay-aux-Roses, France.

9 VUJE-VUJE, a.s., Trnava, Slovak Republic.

${ }^{10}$ IST-C2TN-Instituto Superior Técnico, Lisbon, Portugal.

\begin{abstract}
The European project CONFIDENCE identified, conceptualised and addressed social uncertainties through a multi-method research approach. The research highlighted the uncertainties faced by publics, emergency management actors and decision-makers in nuclear emergencies and during the recovery phase. It showed that nuclear emergency management is dominated by decisions under uncertainties, that non-experts face also different uncertainties than experts, that emergency plans need a (continuous) reality check and that sound communication, openness and transparency about uncertainties may contribute to better decisions. It also suggests that national emergency response and recovery policies should consider and support the capacity of local actors to deal with an emergency or post-accident situation, for instance by carrying out their own measurements. This way, social uncertainties can be addressed and in some situations reduced, and the communication improved.
\end{abstract}

Keywords: social uncertainties / decisions / citizens / emergency management actors / local actors / CONFIDENCE

\section{Introduction}

Uncertainty is inherent to emergency situations, not only in terms of their unpredictability and potential magnitude, but also the way that society responds to such events (Burns and Slovic, 2012; Eiser et al., 2012). In case of nuclear accidents, additional complexity arises from, among others, the potentially long term contamination of the environment and the ensuing social and economic issues; the characteristics of radiological risk due to a nuclear accident (anthropogenic risk, with delayed effects, unequal distribution of risks, catastrophic potential, dreaded risk, children as a vulnerable group), and the controversies on what constitutes a safe level of radiation exposure (Slovic et al., 1982; Sjöberg, 2000; IAEA, 2006; FBPC, 2016).

\footnotetext{
*Corresponding author: catrinel.turcanu@sckcen.be
}

Several studies carried out in the aftermath of the Chernobyl and Fukushima nuclear accidents highlight the importance of a holistic approach to recovery management, which includes the societal dimensions in decision-making and which allows local actors to respond to a crisis through "cooperation among themselves and with other actors and relevant networks" (e.g. Allen et al., 1996; Janssens, 2013; Baudé et al., 2016, p. S156). While the technical uncertainties faced by experts in nuclear emergency and recovery management (e.g. meteorological conditions, source term, technical feasibility of management options, acceptability of management options) have been addressed in previous studies (Nisbet et al., 2005; Raskob et al., 2010; Charron et al., 2016; Schneider et al., 2017), the social, ethical and communication aspects of uncertainty management have not been addressed in a structured and multi-disciplinary way. Moreover, there is a need to identify uncertainties that citizens, decision-makers 
and other stakeholders are facing during an emergency and to investigate how they make sense of and respond to scientific and societal uncertainties, since this can have a strong impact on the effectiveness of the decision-making process.

Within the European project CONFIDENCE, a multimethod approach was undertaken to investigate what are the uncertainties faced by publics and the emergency and recovery management actors, and how do these uncertainties impact their decision-making processes; to elicit stakeholders' preferences and priorities for uncertainty management; to highlight the ethical implications of uncertainty management; to develop and test selected communication tools; and to provide advice for addressing social uncertainties in emergency preparedness, response and recovery. The remainder of this paper summarises the main results. Additional details can be found in (Perko et al., 2020; Tomkiv and Perko, 2020; Turcanu et al., 2020; Zeleznik et al., 2020).

\section{Uncertainties faced by citizens in case of a nuclear emergency}

Research on the different types of uncertainties faced by citizens covered three different approaches: analysis of past accidents, empirical studies using a mental model approach as well as population surveys.

Firstly, the response to scientific and social uncertainties in past incidents and accidents, and the related ethical issues were elucidated through the analysis of five recent incidents (Halden 2016, Norway; IRE-Fleurus 2008, Belgium; Asco 1, 2007, Spain; Tricastin 2008, France; Krsko 2008, Slovenia) together with a retrospective analysis of the management of uncertainties in Norway after the Chernobyl accident, and a study of citizen science after the Fukushima accident (Oughton et al., 2018; Tomkiv and Perko, 2020). The analysis was based on document review, media analysis and interviews. Although the events differed in origin and severity, results showed that the societal impact and the communication challenges were underestimated in all cases. Technical uncertainties, such as the magnitude, inhomogeneity and range of contamination, the variability of measurements, or the purpose of health monitoring (e.g. thyroid measurements) caused societal uncertainties. After the Fukushima accident, citizens' radioactivity monitoring centres provided a means for the affected population to cope with some of the different uncertainties experienced in relation to the accident.

Contradictory information and divergences between experts, or between experts and other societal actors, were highlighted as important sources of uncertainty. For instance, after the incident in Fleurus, farmers could sell their products on the market, but the local population was advised not to consume vegetables from their own garden. Fukushima, Asco and Chernobyl case studies also reported differences in expert opinions, particularly related to health effects. Additional uncertainties related to communication resulted from the delays in providing information to the public, incomplete information and a perceived lack of transparency.

Ethical aspects identified in the seven cases relate to vulnerable populations (e.g. children, as highlighted in Asco and Fleurus cases; and minority cultures seen in Norway/ Chernobyl); sensitivity to differences in distribution of exposures and impacts, initiatives to empower and increase control of affected populations and issues with information transparency highlighted above.

Second, mental models of emergency management were investigated in five countries (Germany, Greece, Slovak Republic, Slovenia and Spain) in order to highlight lay concepts and understandings of emergency preparedness and response (Zeleznik et al., 2020). Data were collected through semi-structured interviews (10-12 in each country) and addressed questions such as: "What are the mental models present within the potentially affected public regarding emergency management and associated uncertainties?", and "What are the differences, gaps, misunderstandings and perceptions in the public compared with the ones provided by experts in the field?". Results stressed the importance of health impact, communication and concerns for children and vulnerable populations (Zeleznik et al., 2020). The memory of the major nuclear accidents in Fukushima and Chernobyl is still present and defines the mental models people have in relation to a nuclear accident.

Finally, surveys were carried out among people living close to nuclear installations in Belgium $(20 \mathrm{~km}$ from Doel or Tihange sites, $N=315$ in total) and Spain $(30 \mathrm{~km}$ around Vandellòs, Ascó, Cofrentes, Trillo and Almaraz sites, $N=302$ ), and among the general public in Belgium $(N=1083)$ and Norway $(N=1000)$ and those living farther than $30 \mathrm{~km}$ from a nuclear power plant in Spain $(N=506)$. The surveys addressed, among others, citizens' concerns in case of nuclear emergency, their self-assessed level of information and their trust in various actors as communicators.

Both the surveys and the mental models studies revealed that citizens have some knowledge of the basic elements of emergency plans, but they lack specific knowledge about protective measures (e.g. the purpose and best time of intake for stable iodine pills). Concerns about a major accident included fatalistic beliefs (e.g. "I will die"). Respondents to mental models studies and surveys - particularly those living close to a nuclear installation - considered themselves insufficiently informed and argued that authorities should undertake more actions to inform the population. They also suggested that new means of communication, such as social media, should be included

The first reactions and main concerns were related to health risks, contamination of the environment, people's well-being (e.g. children, family), staying/going indoors, finding and taking iodine pills, leaving the area, what to do in case of an accident, and how will they be informed about it.

With respect to the trust that citizens place in authorities and experts, some differences were seen between countries, particularly in local authorities. In Belgium and Spain, most trusted communicators (to provide correct and objective information) during an emergency are national crisis centres, rescue services, research organisations (universities or research centres) and medical doctors. Large fractions of the population (e.g. one in four Belgians) also express a high level of trust in environmental organisations as communicators in case of a nuclear emergency. In Norway, one in two members of the public would trust the Norwegian authorities in case of conflicting messages during emergencies, and one third would trust research institutions. In Belgium, respondents living close to nuclear installations expressed less trust in scientists from universities and research centres and nuclear safety authorities, than the general public. 


\section{Uncertainties faced by local actors and the influence of emergency and post- accident policies on their capacity to manage these uncertainties}

Large-scale nuclear accidents can lead to long-term contamination of territories, with significant impacts to human life conditions. All dimensions of life (personal, family, social, health, economic, cultural and political) can be affected by these situations, often irreversibly. It can lead to the destruction of social cohesion and to social distrust, leaving individuals isolated and without social recourse, confronted with complex situations where they experience loss of control over their life.

Emergency management plans provide frameworks that define the responsibilities of different institutional actors for instance authorities, but they are mostly limited to the early phase of an emergency and focus solely on the role of institutional actors. The Fukushima accident showed that some local actors (i.e. local authorities, economic actors, civil society organisations, scientists, families) had been active from the first hours after the accident, including the early phase (Baudé et al., 2016). The construction of local actors' response to a post-accident situation is a social process entailing a multitude of decisions taken in a context marked by uncertainty and according to a broad set of issues which are not limited to the application of external prescriptions. Research carried out within the CONFIDENCE project mobilised the framework of "dignified living conditions" to address questions such as: "How are local actors confronted to the complexity of emergency and post-emergency situations and the associated uncertainties?" and "What are the resources for local actors to deal with these and how could national emergency and post-emergency arrangements be improved to enable and support local actors in their efforts to rebuild dignified living conditions?" (Baudé et al., 2019). The concept of dignified living conditions has been proposed as a potential common objective for emergency and post-emergency managers and local actors confronted with the consequences of a nuclear accident. This includes seven complementary criteria characterizing the different anthropological resources that are at the origin of resilience capacities: integrity and personal ability to act; the existence of conditions allowing the effective satisfaction by people of their basic needs; the ability to act with others; the ability of people to build meaning, personally and with others, to orient themselves and, in this perspective to access reliable, meaningful, true information; the possibility for people to benefit from a fair and equitable institutional and political environment and to have influence on it; territorial rooting of individuals and communities; and symbolic and spiritual resources. These criteria are grounded on the synthesis of different academic results in the field of philosophy, sociology, developmental economy, psychology and anthropology and take into account the experience from the Chernobyl and Fukushima accidents. The seven criteria have been developed as part of the methodology of national workshops organised in France, Slovak Republic and Portugal, in order to analyse and discuss the resilience capacities of local populations confronted with disruptive situations resulting from a nuclear accident. The three workshops brought together a variety of participants, having some knowledge or not on emergency and post-emergency issues. The discussion of the cases (inspired by real situations experienced by local actors in Japan after the Fukushima accident) confirmed that local actors may be active players even in the emergency phase. When facing existential questions, they may take autonomous action, individually and collectively mitigating failures or gaps of institutional response to some extent. Local actors highlight the need to recreate an environment allowing the satisfaction of basic needs, in particular for vulnerable people in their community, such as children or the elderly. This includes rebuilding the meaning of existence in general and the deployment of meaningful actions in particular. While doing this, local actors tend to balance the various dimensions of the situation (e.g. health, environment, links between generations, social bonds, attachment to territory, link with the meaning of their life including its spiritual dimension). Radiation protection represents only one dimension, among other important aspects of life. Should one stay? Will the territory become habitable again? When will it take place? Can we project ourselves into a future on this territory (or in relocation) and if so how?. These questions highlighted fundamental uncertainties that combine various environmental, health, economic, social, and other factors related to the meaning of pursuing a life (including from an intergenerational perspective) or an activity in a contaminated territory. A major conclusion of this work asserts the need to introduce or strengthen the degree of flexibility and subsidiarity in the emergency and recovery response frameworks in order to adapt these to the specificity of local contexts and to unforeseen situations that are likely to arise in the event of a major nuclear accident. An important challenge is to articulate the action of the public sphere with that of civil society. In this perspective, and complementary to authorities' roles, subsidiarity implies providing local actors with appropriate support (technical tools and expertise) that make the possible alternative scenarios and choices explicit in their specific contexts, and enable them to build local strategies together. For instance, emergency and recovery preparedness and management policies should prepare and support the deployment of local measurement capacities in the event of an accident. This may entail providing information and training for local authorities and other (networks of) local actors and strengthening the links between non-institutional actors and professional measurement capacities. Inter-comparison between institutional measurements and non-institutional measurements (local or external) should be organised to promote confidence in both types of measurement results. As local networks are vested with trust by local actors, they can also play an important role in disseminating and sharing information. It should be noted that transparency is required by local actors not only on established facts, but also on the related uncertainties during the emergency and post-emergency management.

One question that appears central in this articulation is: How to support local actors in the construction of meaningful strategies, while preserving their autonomy? Management of radioactivity in food, for instance, cannot be based solely on the existence of standards. Everyone should have access to food monitoring in order to control their exposure within the limits they consider as appropriate (for themselves, for family and children, etc.), even if these limits are more restrictive than the official standards.

It seems difficult for public policies to encourage the deployment of local measurements in emergency situations 
given the risk of exposure of local actors carrying out the measurement, as they are less trained and lack the means for personal protection used by professionals.

It is also noted that emergency and post-emergency policies should be prepared to identify possible environmental contamination not only in the perimeters defined by the zoning, but also beyond these boundaries. In particular, since emergency and post-emergency managers may have limited capacity to perform extensive measurements beyond these boundaries, it is important that local actors have the capacity to perform such measurements by themselves and it should be regarded as an asset. This kind of initiative should be welcomed and supported with actions if a problem is detected. This requires the preparation of local actors with the capacity to intervene in these "outside" areas, in particular to carry out measures. Investing in education and training at local level emerges as a political imperative.

\section{Uncertainties faced by emergency actors}

Uncertainties faced by emergency actors were identified by observation of emergency exercises and by a study of potential response from citizens to official advice (surveys, see Sect. 3).

Exercises provide an environment for testing emergency response that is closest to a real situation. Research conducted through observations of exercises provided insights into the way uncertainties are addressed and handled during emergency exercises (Perko et al., 2019). The methodological approach relied on non-participant observation as a technique for the systematic study of human behaviour. It focused on the information flow and communication between actors, as well as the assumptions and decisions made under emergency exercise conditions. The objective was to maintain the integrity of unique cases/findings, to crystallize rather than generalize, and contribute to theory and dialogue about nuclear emergency management under uncertainties. Eleven national exercises were observed in six countries, as well as one international exercise, with a total of 29 observation points. The research resulted in the identification of a list of societal uncertainties that different actors may face during their decision-making process in case of a nuclear emergency.

The following issues, causing uncertainties or being caused by uncertainties have been identified during observations and were classified in the following categories. Knowledge uncertainty is related to lack (or availability) of knowledge or information (e.g. "What is the origin of the first information?; Which areas will be affected?; How serious is the accident?; When is the time of the beginning of the release?"). Judgement uncertainty is related to assessing and balancing decision options (e.g. "How is information understood by different stakeholders?; How to decide on protective actions?; Which information is public and which information should be restricted to the emergency management teams?") . Decision uncertainty is related to prioritizing which option to choose (e.g. How to deal with long-term consequences? Which protective actions to apply?; How to communicate negligible impacts?). Implementation uncertainty is related to taking actions based on the decision made or putting decisions into practice (e.g. How to coordinate cross-border aspects?; Is there a gap between legislation (including plans) and reality?
Are the available resources adequate?; Are the emergency actors familiar with and trained to use the equipment?). Evaluation/monitoring uncertainty are related to the actual outcome of actions (e.g. Will people follow the instructions or recommendations given? Is the information exchange sufficient?). It is important to note that these uncertainties are connected and they depend on the actor. For instance, "decision" uncertainties for citizens may be "evaluation" uncertainties for emergency management actors.

Uncertainties related to public response were also investigated with surveys (see also Sect. 2) (Turcanu et al., 2019). These showed that leaving children at school and avoiding the use of phone will be problematic in case of an accident. Differences were noted between countries in terms of self-assessed compliance with recommended actions. For instance, in Spain, self-assessed compliance was markedly higher among respondents living less than $30 \mathrm{~km}$ away from a nuclear installation, compared to those living farther away. Such differences were, however, not consistent and much smaller in Belgium. Three actions are generally considered as easy to undertake and effective to protect against the nuclear risk associated with an emergency situation: dietary restrictions, leaving the area and avoiding drinking tap water. Staying indoors was perceived, on average, as relatively easy to carry out, but less effective. Taking an iodine tablet was considered as not very easy and only moderately effective. Results also showed that self-assessed compliance increases with higher perception of other residents' compliance and perceived effectiveness of protective action, but decreases with perceived difficulty. Knowing more about protective actions is in general not a guarantee of compliance with the advice from authorities in an emergency situation. Compliance with leaving children at school, as an exception, was, however, positively correlated with knowing what to do in case of a nuclear accident, and the association was stronger in the local population. Higher levels of trust in the nuclear safety authorities as emergency communicator were associated with higher expected compliance mostly among the local populations, and particularly in Spain. Respondents with higher levels of trust seemed somewhat more inclined to comply with staying indoors, avoiding the use of phone, taking an iodine tablet (both Belgium and Spain), leaving children at school (only Belgium) and respecting dietary restrictions (only Spain). The results also suggest that significant parts of respondents in both the local and general populations may be reluctant to consume local food products with residual radioactivity.

\section{Conclusions}

Uncertainty pervades all aspects of emergency response and recovery management. The social study undertaken in the CONFIDENCE project aimed at identifying the social uncertainties faced by citizens and emergency and recovery management actors in case of a nuclear accident. It showed that also non-experts face uncertainties, and these can be different than those of experts, for instance related to the basic needs of life in affected territories. It also argues that emergency and recovery plans need a continuous reality check in order to identify whether the needs and concerns of the affected people are taken into account. Poor communication between experts and emergency and recovery management actors, the 
perceived lack of transparency and untimely information provided to the public create uncertainty. Communicating about uncertainty is necessary and requires identifying facts relevant to recipients' decisions and characterisation of relevant uncertainties, as well as testing the effectiveness of potential messages. National emergency and recovery strategies and plans should consider and support the capacities of local actors to deal with an emergency or post-accident situation, for instance by carrying out independent measurements of radioactivity.

Identification of societal uncertainties contributes to creating awareness about potential challenges and improving decision-making under uncertainty in nuclear emergencies.

Acknowledgement. This paper build on results reported in the CONFIDENCE deliverables D9.25, D9.26, D9.27, D9.28, D9.30, D9.32. Available from https://www.concert-h2020.eu/ en/Publications. CONFIDENCE is part of the CONCERT project.

This project has received funding from the Euratom research and training programme 2014-2018 under grant agreement No. 662287. This work was partly supported also by the Research Council of Norway (RCN) (Grant Number 223268/ F50 [CERAD - Centre for Environmental Radioactivity] and Grant Number 263856/E40.

Disclaimer (Art. 29.5 GA). This publication reflects only the author's view. Responsibility for the information and views expressed therein lies entirely with the authors. The European Commission is not responsible for any use that may be made of the information it contains.

\section{References}

Allen P et al. 1996. Optimisation of health protection of the public following a major nuclear accident: Interaction between radiation protection and social and psychological factors. Health Phys. 71 (5): 763-765.

Baudé $\mathrm{S}$ et al. 2019. Uncertainties faced by the local actors and influence of emergency and post-emergency arrangements on their capacity to manage these uncertainties. CONCERT Deliverable D9.30. Available from https://www.concert-h2020. eu/en/Publications.

Baudé S, Heriard-Dubreuil G, Eikelmann IM, Boilley D, Schneider T. 2016. Local populations facing long-term consequences of nuclear accidents: Lessons learnt from Chernobyl and Fukushima. Radioprotection 51: S155-S158.

Burns WJ, Slovic P. 2012. Risk perception and behaviors: Anticipating and responding to crises. Risk Anal. 32(4): 579-582.

Charron S, Lafage S, van Asselt E, Baptista M, van Bourgondiën M, Brandhoff P, Cabianca T, Camps J, Cessac B, Crouail P, Durand V, Gallego E, Gil O, Holmes S, Hourdakis C, Jones K, Kamenopoulou V, Lecomte JF, Liland A, Lopes I, Madruga MJ, Martins JO, Mc Mahon C, Montero M, Murith C, Olyslaegers G, Organo C, Paiva I, Peltonen T, Portugal L, Potiriadis C, Prades A, Reis M, Rossignol N, Schneider T, Sala R, Smith V, Tafili V, Teles P, Tomkiv Y, Trueba C, Turcanu C, Turtiainen T, Twenhöfel
C, Vaz P. 2016. Overview of the PREPARE WP3: Management of contaminated goods in post-accidental situation-Synthesis of European stakeholders' panels. Radioprotection 51: S83-S91.

Eiser JR et al. 2012. Risk interpretation and action: A conceptual framework for responses to natural hazards. Int. J. Disaster Risk Reduct. 1: 5-16.

Fukushima Booklet Publication Committee (FBPC). 2016. 10 lessons from Fukushima. Available from http://fukushimalessons.jp/ assets/content/doc/Fukushima10Lessons ENG.pdf.

IAEA. 2006. Environmental consequences of the Chernobyl accident and their remediation: Twenty years of experience. Report of the Chernobyl Forum Expert Group "Environment”. IAEA STI/PUB/ 1239.

Janssens A. 2013. EU Basic Safety Standards and European response to the Fukushima accident. Radioprotection 48(5): S19-S26.

Nisbet AF et al. 2005. Achievements, difficulties and future challenges for the FARMING network. J. Environ. Radioact. 83(3): 263-274.

Oughton D, Perko T, Abelshausen B, Kenens J, Van Oudheusden M, Turcanu C, Sala R, Oltra C, Tomkiv Y, Maître M, Schneider T, Zeleznik N. 2018. Case descriptions for characterization and response to uncertainty in past nuclear emergencies. CONCERT Deliverable D9.25. Available from https://www.concert-h2020. eu/en/Publications.

Perko T, Tafili V, Sala R, Duranova T, Zeleznik N, Tomkiv Y, Hoti F, Turcanu C. 2019. Report on observational study of emergency exercises: List of uncertainties. CONCERT Deliverable D9.28. Available from https://www.concert-h2020.eu/en/Publications.

Perko T, Benighaus L, Tomkiv Y, Wolf HV. 2020. Guidance on communicating about uncertainties in nuclear emergency management. Radioprotection 55(HS1). https://doi.org/10.1051/radio pro/2020028.

Raskob W et al. 2010. Decision aiding handbooks for managing contaminated food production systems, drinking water and inhabited areas in Europe. Radioprotection 45(5): S23-S37.

Schneider T, Gering F, Charron S, Zhelezniak M, Andronopoulos S, Heriard-Dubreuil G, Camps J, Raskob W. 2017. Nuclear and radiological preparedness: The achievements of the European research project PREPARE. Radiat. Protect. Dosim. 173(1-3): $151-156$.

Sjöberg L. 2000. Factors in risk perception. Risk Anal. 20(1): 1-12.

Slovic P, Fischhoff B, Lichtenstein S. 1982. Why study risk perception? Risk Anal. 2(2): 83-93.

Tomkiv Y, Perko T. 2020. Societal uncertainties recognised in recent nuclear and radiological emergencies in Europe. Radioprotection 55(HS1). https://doi.org/10.1051/radiopro/2020025.

Turcanu C et al. 2019. Recommendations for improved communication and stakeholder involvement related to uncertainties. CONCERT Deliverable D9.32. Available from https://www. concert-h2020.eu/en/Publications.

Turcanu C, Perko T, Wolf HV, Camps J, Oughton D. 2020. Social uncertainties associated with stable iodine intake in a nuclear emergency. Radioprotection 55(HS1). https://doi.org/10.1051/ radiopro/2020027.

Zeleznik N et al. 2020. Mental models of uncertainty management in nuclear emergency management. Radioprotection 55(HS1). https://doi.org/10.1051/radiopro/2020026.

Cite this article as: Turcanu C, Perko T, Baudé S, Hériard-Dubreuil G, Zeleznik N, Oughton D, Tomkiv Y, Sala R, Oltra C, Tafili V, Benighaus L, Benighaus C, Maitre M, Schneider T, Crouail P, Duranova T, Paiva I. 2020. Social, ethical and communication aspects of uncertainty management. Radioprotection 55(HS1): S145-S149 